\title{
A Novel Polarization Independent Wideband Circuit Analog Absorber Using Crossed Loops
}

\author{
Libi Mol VADAKKEKALATHIL ABDULHAKIM , Chandroth Karuvandi AANANDAN \\ Dept. of Electronics, Cochin university of Science and Technology, Cochin, 682022 Kerala, India \\ libi.riyaz@gmail.com, anand@cusat.ac.in
}

Submitted January 23, 2018 / Accepted June 12, 2018

\begin{abstract}
In this paper, a polarization independent wideband circuit analog absorber is proposed. The structure consists of two dimensional periodic array of crossed loops embedded with lumped resistors printed on dielectric substrates backed by a metal plate. It offers $a-10 \mathrm{~dB}$ reflectivity (90\% absorptivity) fractional bandwidth of $126.5 \%(4.6 \mathrm{GHz}$ to $20.45 \mathrm{GHz}$ ). The total thickness of the absorber (dielectric+air gap) is about $0.084 \lambda_{L}$ at the lowest frequency of absorption. The effect of different structural parameters on absorption characteristics are studied and presented. The prototype of the proposed absorber is fabricated and the measured responses are in agreement with simulated results.
\end{abstract}

\section{Keywords}

Polarization independent, circuit analog absorber, wideband, crossed loop

\section{Introduction}

Radar cross section (RCS) is a measure of detectability of the target when illuminated by an electromagnetic wave. So, RCS reduction is important in the field of military applications. RCS of an object can be either reduced by absorption or by scattering the incident wave away from the observer. A classic planar absorber is Salisbury screen, which consist of a resistive layer at quarter wavelength away from the ground plane [1]. Even though this structure is easy to design, it has the drawback of large thickness and narrow bandwidth of operation. Jaumann absorbers consisting of multiple layers of resistive sheets offer wideband operation at the cost of complex design [2]. A layered magneto dielectric slabs backed by a metal plate is also a good candidate as the absorber [3].

High Impedance Surfaces (HIS) are metamaterials exhibiting perfect magnetic conductor (PMC) property at the resonant frequency [4]. It consists of array of patches over the grounded dielectric. Different absorbing configurations like ultra-narrowband to ultra wideband is attainable by ex- ploiting dielectric or ohmic loss of HIS structures [5]. These absorbers can be considered as another major development among orthogonal frequency division multiplexing systems, tunable antennas etc [6-8]. HIS based scatteres are also one of the major research area [9].

The structures showing ultra-narrowband absorption by exploiting the dielectric loss of commercially available substrate are referred as perfect metamterial absorbers. Since the pioneering work of perfect metamaterial absorber by Landy et al. in 2008 [10], these are widely investigated by researchers to design ultrathin, polarization independent multiband and conformal absorbers with wide incident angular stability in microwave and terahertz frequency regions [11-18]. Different techniques were reported in literature to enhance the bandwidth of operation of metamaterial absorbers. The use of magnetic absorbers instead of electric absorbers can provide enhancement in bandwidth with an extra cost of increase in absorber weight [19], [20]. Large bandwidth can also be achieved by using multi-layered structure [21] or by arranging multiple resonating structures with closer resonant frequency in a single unit cell [22-24]. Use of multiple resonators has the disadvantage of increased unit cell size.

The bandwidth of operation can also be enhanced by imparting ohmic loss to the FSS layer using resistive sheets [25], [26] or by using circuit analog absorbers. In circuit analog absorbers, ohmic loss is imparted on HIS using lumped resistors soldered on the patches [27-30]. The absorbers also plays a major role in the RCS reduction of antennas. The rasorber transmitting waves at certain frequencies and absorbing at other frequencies can be used as radome to reduce the RCS [31], [32]. Metamaterial absorberss can also be used to reduce the RCS of slotted array antenna [33] and circularly polarized tilted beam broadband antenna [34].

A wideband polarization independent absorber composed of trumpet shaped resonators with four lumped resistors having $90 \%$ absorption bandwidth of $65 \%$ is reported [27]. A single layer wideband absorber having thickness of $0.077 \lambda_{\mathrm{L}}$ offering a $10 \mathrm{~dB}$ reflection reduction bandwidth of $70.7 \%$ has been realized using an array of crossed dipoles [28]. Praneet et al. proposed a Minkowski frac- 
tal loop based broadband polarization independent metamateral absorber having very good absorption over the entire $\mathrm{C}$ band [29]. Further enhancement in bandwidth of circuit absorbers can be obtained by using multiple resonance concept [35-37] or multi-layer geometry [38]. Yuping Shang et al. designed a single layer circuit analog absorber with thickness $0.088 \lambda_{\mathrm{L}}$ offering a fractional bandwidth of $126.8 \%$ using double square loop array [35]. A polarization insensitive perfect absorber having a fractional bandwidth of $73.68 \%$ has been realized by using octagonal rings metamaterials and lumped resistors [36]. Ghosh et al. proposed a broadband absorber comprising multilayer frequency selective surfaces with a fractional bandwidth of $114.4 \%$ and thickness of $0.246 \lambda_{0}$ [38].

In this paper, a single layer, polarization insensitive, wideband circuit analog absorber is presented. The structure consists of frequency selective surfaces loaded with lumped resistors printed on a dielectric backed by a metal plate at $4.7 \mathrm{~mm}$. It offers good angular stability up to $45^{\circ}$ for TE and TM polarized wave incidence and shows $-10 \mathrm{~dB}$ reflectivity reduction band width of $126.5 \%$ at normal incidence. Polarization independent behavior is observed due to structural symmetry. The simulation results were verified by measurement using fabricated prototype. Compared to other similar designs, the proposed structure has the advantages of wider bandwidth and simple structural design.

\section{Geometry of the Absorber Structure and Simulated Results}

The unit cell geometry of the proposed absorber is shown in Fig. 1. It consists of crossed loop with lumped resistors printed over the dielectric, which is separated from the metallic ground by the spacer at a distance of $h_{1}$. Rogers RT Duroid 5880 substrate $\left(h=0.79 \mathrm{~mm}, \epsilon_{\mathrm{d}}=2.2\right.$ and $\tan \delta=0.0009)$ is used as the dielectric. The FSS comprises of crossed loop with lumped resistors $(\mathrm{R}=220 \Omega)$ connected at the four legs as in Fig. 1. The optimized parameters of the structure are: $d=12 \mathrm{~mm}, b=11 \mathrm{~mm}, a=2 \mathrm{~mm}, g=1 \mathrm{~mm}$, $w=1 \mathrm{~mm}$.

The reflection characteristics of the proposed unit cell is simulated using unit cell boundary condition in CST MW Studio 2016 and the result is shown in Fig. 2. The reflection coefficient is less than $-10 \mathrm{~dB}$ from $4.6 \mathrm{GHz}$ to $20.45 \mathrm{GHz}$ with reflection dips at $5.54 \mathrm{GHz}$ and $16.05 \mathrm{GHz}$.

The working principle of proposed absorber can be explained using equivalent circuit modeling. The equivalent circuit of proposed absorber consist of a series RLC circuit parallel to a shorted transmission line as in Fig. 3. RLC component represents the crossed loop with lumped resistor and the shorted transmission line with length $h_{1}$ corresponds to grounded dielectric slab. The short transmission line section with length $h$ represents the thin dielectric slab. $Y_{0}, Y_{\text {in }}, Y_{\mathrm{FSS}}$ and $Y_{\mathrm{d}}$ represents the characteristic admittance of free space above the absorber, total input admittance of the entire structure, admittance of FSS layer and the admittance offered by the stacked dielectric and air layers backed by metal plate.

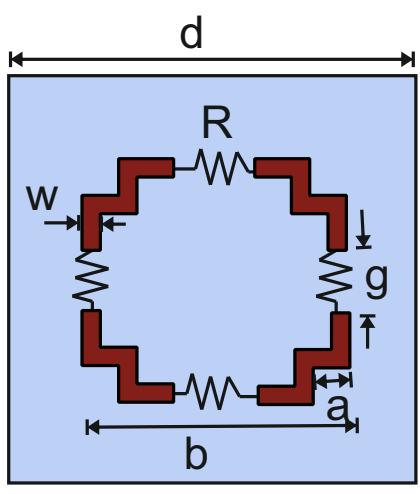

(a)

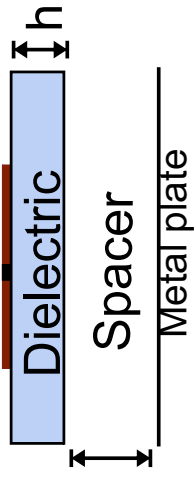

$\mathcal{L}^{-}$
Fig. 1. Unit cell geometry of proposed absorber (a) Front view (b) Side view.

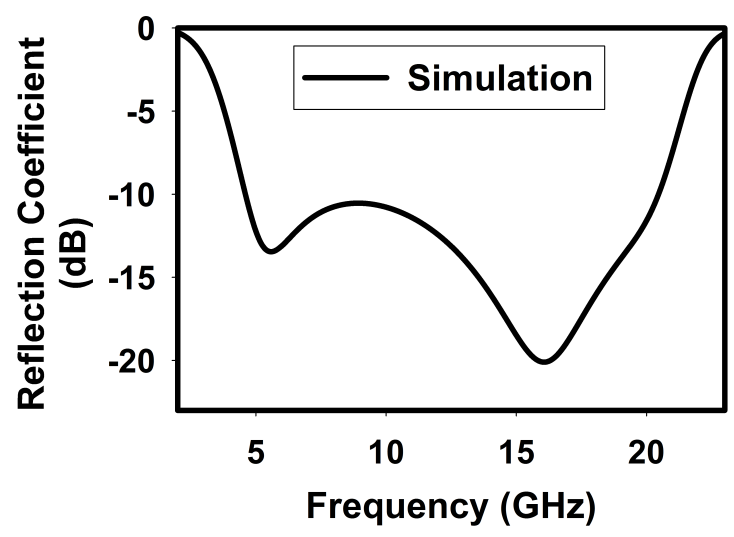

Fig. 2. Simulated response of proposed absorber.

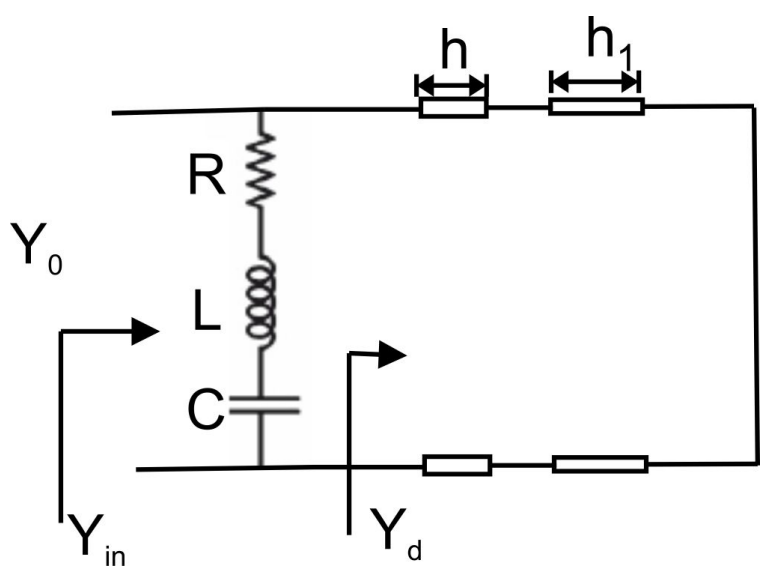

Fig. 3. Equivalent circuit model of proposed absorber. 


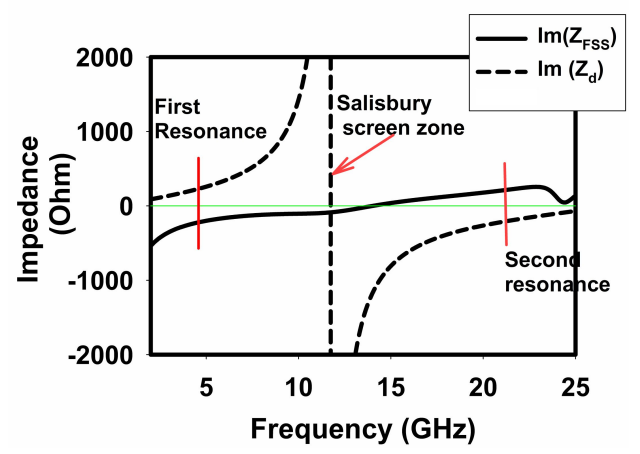

Fig. 4. Simulated impedance of FSS $\left(Z_{\mathrm{FSS}}\right)$ and grounded dielectrics $\left(Z_{\mathrm{d}}\right)$

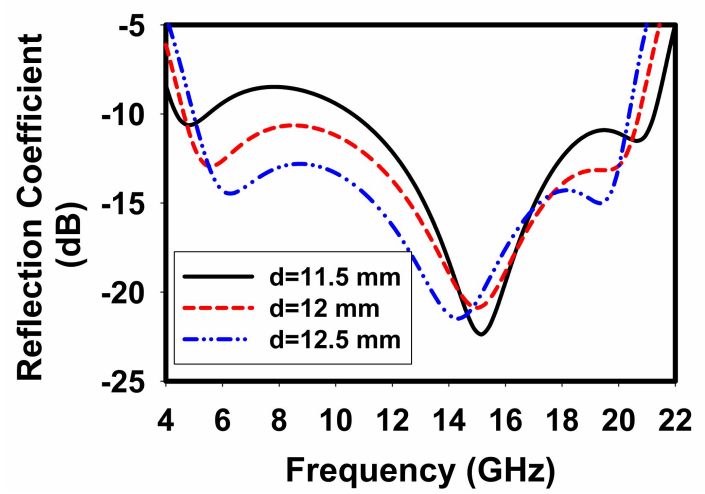

Fig. 6. Simulated reflection coefficient for different values of periodicity $(d)$.

The reflection coefficient of absorber can be expressed as in [39]

$$
\begin{gathered}
\Gamma=\frac{\left(Y_{0}-Y_{\text {in }}\right)}{\left(Y_{0}+Y_{\text {in }}\right)}, \\
Y_{\text {in }}=Y_{d}+Y_{\mathrm{FSS}}, \\
Y_{\mathrm{FSS}}=G+\mathrm{j} B, \\
Y_{\mathrm{d}}=-\mathrm{j} \cot \left(k h_{\mathrm{eff}}\right) \sqrt{\frac{\epsilon_{0} \epsilon_{\mathrm{eff}}}{\mu_{0} \mu_{\mathrm{eff}}}}
\end{gathered}
$$

where $\epsilon_{\mathrm{eff}}$ and $\mu_{\mathrm{eff}}$ are the effective permittivity and permeability of stacked grounded dielectric layers, $\mathrm{G}$ and $\mathrm{B}$ are conductance and susceptance of the FSS, $\mathrm{k}$ is the wavenumber in the substrates and $h_{\mathrm{eff}}=h+h_{1}$. The admittance of grounded dielectric layers become equal but opposite in sign to that of the FSS susceptance during resonance and the maximum absorption occurs when the remaining real part of input admittance matches to that of free space admittance $\left(Y_{0}\right)$.

To illustrate the absorption mechanism of the proposed structure, the simulated imaginary component of the dielectric and FSS impedance are shown in Fig. 4. At $4.5 \mathrm{GHz}$, the inductive reactance of grounded dielectric layer becomes equal to that of capacitive reactance of FSS and results in first resonance. At $11.74 \mathrm{GHz}$, the imaginary part of impedance of grounded dielectric layers changes from inductive to capacitive and will act as a high impedance wall identified as Salisbury screen zone. At this frequency, the real part of grounded dielectric impedance is characterized by a very high value. At this frequency, imaginary part of FSS impedance

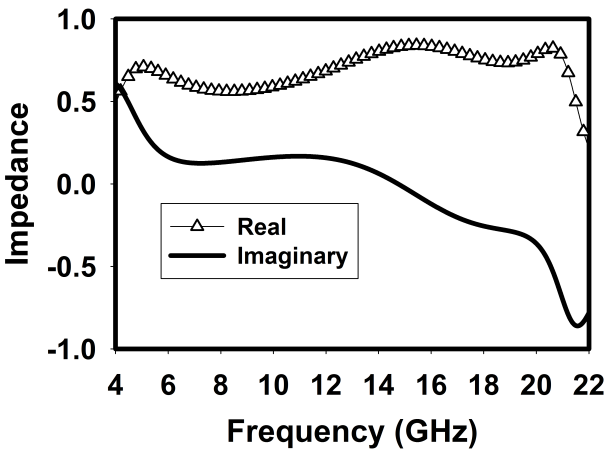

Fig. 5. Simulated real and imaginary part of impedance.

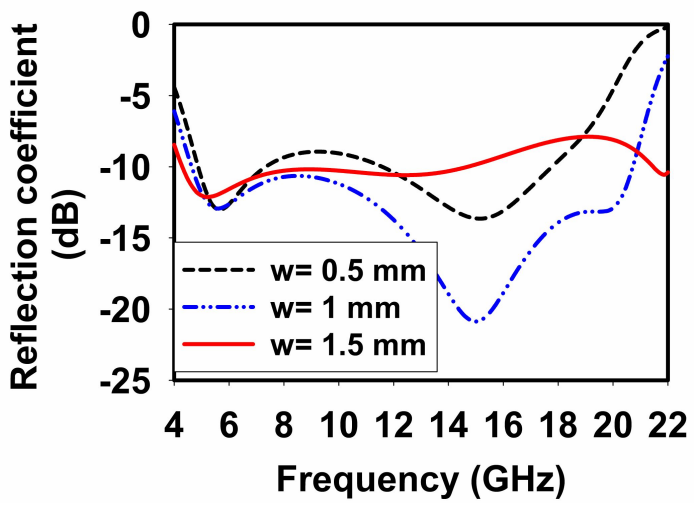

Fig. 7. Simulated reflection coefficient with width $(w)$ variation.

is not zero and thus no resonance is obtained. At $21.15 \mathrm{GHz}$, the capacitive reactance of dielectric layer becomes equal to that of inductive reactance of FSS layer and results in another parallel resonance (second resonance). This result shows that the absorber can provide wider absorption bandwidth from $4.5 \mathrm{GHz}$ to $21.15 \mathrm{GHz}$. The simulated result (Fig. 2) shows slight variation in absorption frequency range ( $4.6 \mathrm{GHz}$ to $20.45 \mathrm{GHz}$ ) as compared to the predicted frequency range from equivalent circuit modeling.

The real and imaginary part of the normalized impedance of the proposed absorber is shown in Fig. 5. For maximum absorption, the real part of impedance should be matched to that of frees space impedance and the imaginary part should be zero or negligible (as per (1) and (2)). Within the entire frequency band of interest, the value of real part of impedance is near to free space impedance and the imaginary component is nearly zero or have a negligible value.

The effect of different geometrical parameters on the absorption characteristic of the structure is studied by simulation and it is described below. The variation of reflection coefficient of the structure for different values of periodicity of unit cell $(d)$ is shown in Fig. 6. As the periodicity increases, the capacitance decreases due to the increase in gap between nearby cross loops. The lower resonant frequency increases and the higher resonant frequency decreases due to the decrease in capacitance of FSS. The bandwidth of operation is reduced with increase in periodicity and $d=12 \mathrm{~mm}$ gives better performance. 
The effect of width of the loop $(w)$ on the performance of absorber is simulated and is shown in Fig. 7. The structure provides better performance when $w=1 \mathrm{~mm}$.

The reflectivity of proposed absorber is studied for different values of chip resistor $(R)$ and it is shown in Fig. 8. It is found that structure with $220 \Omega$ resistor can provide better bandwidth enhanced performance as compared to other resistor values.

The variation in reflectivity for different values of air gap distance $\left(h_{1}\right)$ between the FSS and the metal ground plane is shown in Fig. 9. When $h_{1}=5 \mathrm{~mm}$, the bandwidth of operation is less and when $h_{1}=4.4 \mathrm{~mm}$, the structure is not showing reflectivity below $-10 \mathrm{~dB}$ at some frequency points within the area of interest. Optimum air gap distance is obtained as $4.7 \mathrm{~mm}$ for better $-10 \mathrm{~dB}$ reflectivity bandwidth.

The structure can provide polarization independent behavior due to the four fold symmetry. The reflectivity of the structure for different polarization angles $(\phi)$ at normal incidence is shown in Fig. 10.

The angular stability of the structure is also studied for TM and TE polarized wave incidence and is depicted in Fig. 11 and 12, respectively. Up to $45^{\circ}$ angle of incidence, the reflection coefficient is less than $-6 \mathrm{~dB}$ (absorptivity $=86.53 \%$ ) within the frequency of interest for TE and TM polarized wave. As the angle of incidence increases the absorptivity gradually decreases and limits the angular stability up to $\pm 45^{\circ}$.

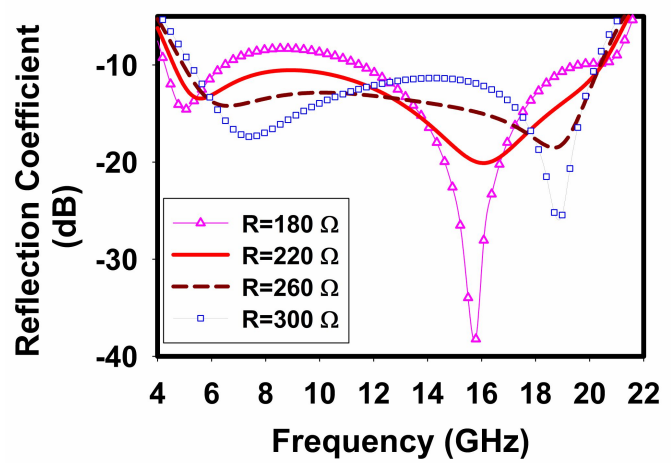

Fig. 8. Simulated reflection coefficient for different values of chip resistor $(R)$.

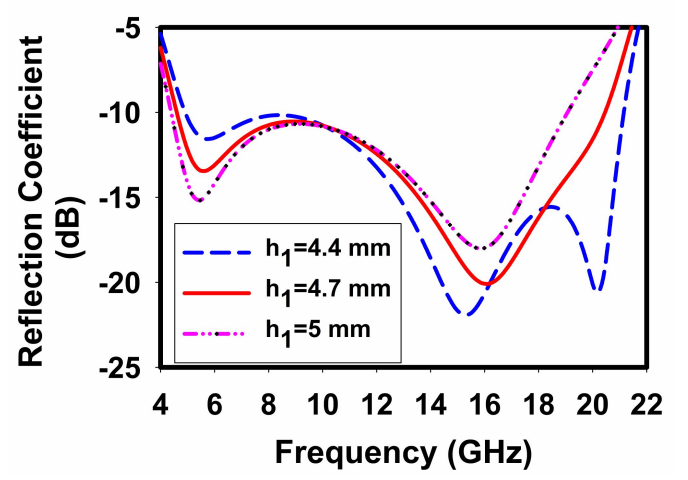

Fig. 9. Simulated reflection coefficient for different values of air spacer $\left(h_{1}\right)$.

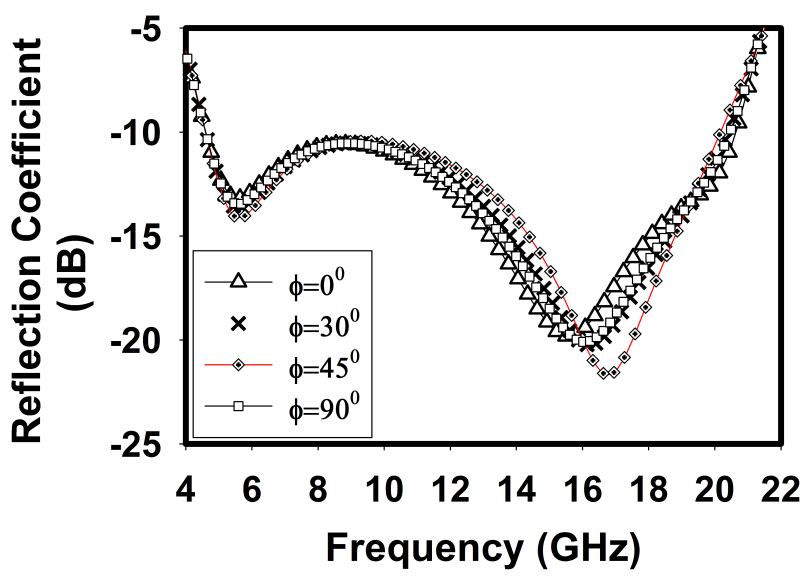

Fig. 10. Simulated reflection coefficient of proposed absorber for different polarization angles $(\phi)$ at normal incidence.

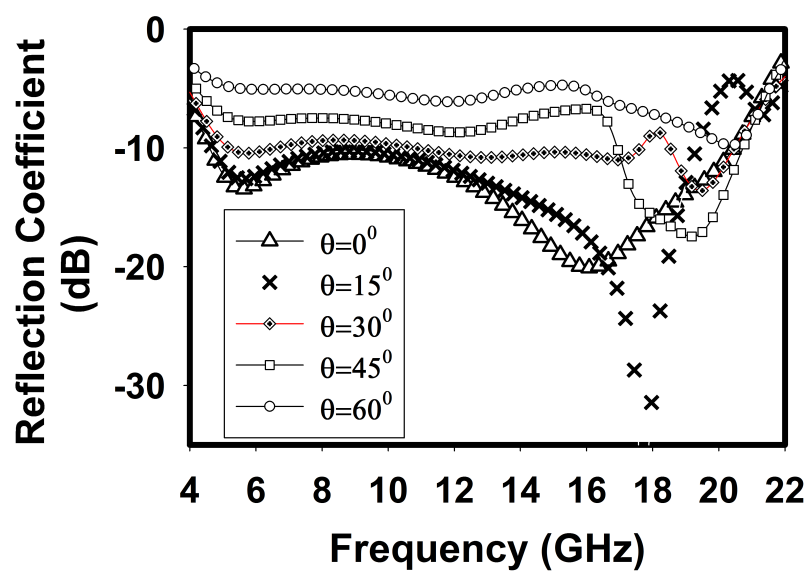

Fig. 11. Simulated reflection coefficient of the absorber for different angle of incidence $(\theta)$ under TM polarization.

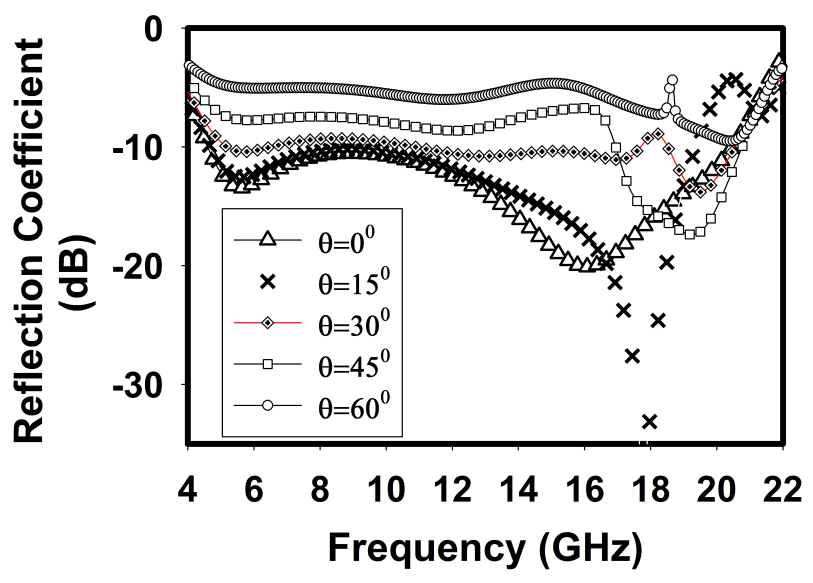

Fig. 12. Simulated reflection coefficient of the absorber for different angle of incidence $(\theta)$ under TE polarization. 
To get a physical insight of the absorption phenomena, the power loss density at $5.5 \mathrm{GHz}, 14.3 \mathrm{GHz}$ and $20 \mathrm{GHz}$ for both TM and TE polarized waves incidence is plotted in Fig. 13(a-f). For TM polarized wave, the loss density is maximum around the resistors along Y-axis and for TE polarized wave, the power loss density is maximum around the resistors along $\mathrm{X}$-axis.

The distribution of electric field for TM and TE polarized waves incidence at $5.5 \mathrm{GHz}, 14.3 \mathrm{GHz}$ and $20 \mathrm{GHz}$ is shown in Fig. 14(a-f). Different modes of resonances can be clearly observed from figure.

The reflectivity of proposed absorber with and without lumped resistors are also studied and is depicted in Fig. 15. Without lumped resistors, the structure is acting as an artificial magnetic conductor; i.e. it will reflect all the incident wave in-phase. This indicates that the lumped resistors are mainly contributing for the absorption mechanism of the structure.

The characteristics of the proposed absorber is compared with previously reported absorbers and is shown in Tab. 1. It indicates that the proposed structure provides better bandwidth performance with simple structural design and optimum thickness as compared to other absorbers.
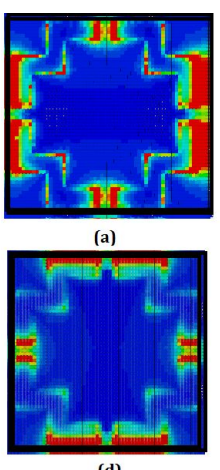

(d)
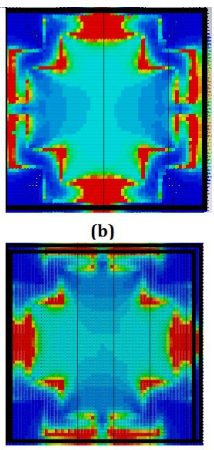

(e)
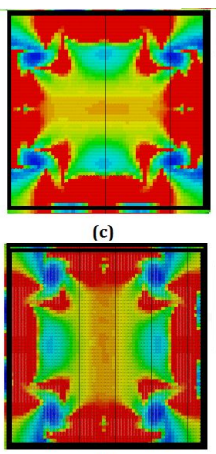

(f)

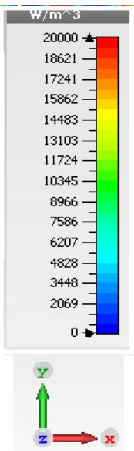

Fig. 13. Power loss density distribution at $[(\mathrm{a}),(\mathrm{d})] 5.5 \mathrm{GHz}[(\mathrm{b})$, (e)] $14.3 \mathrm{GHz}$ and [(c), (f)] $20 \mathrm{GHz}$ for TM and TE polarized wave incidence, respectively.

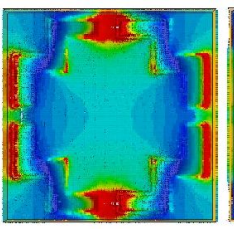

(a)

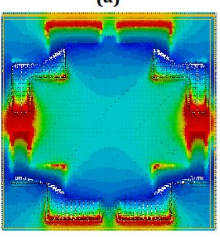

(d)

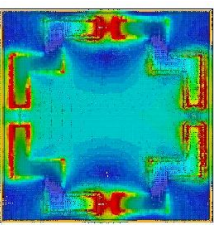

(b)

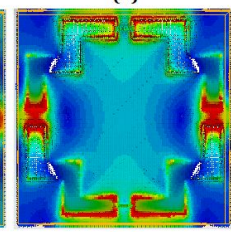

(e)

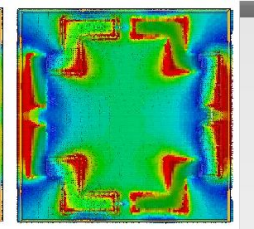

(c)

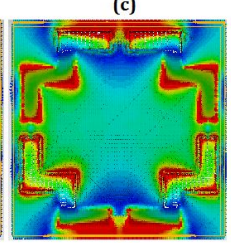

(f)

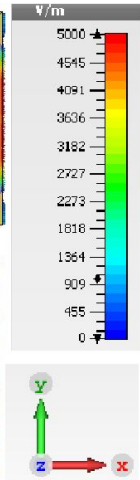

Fig. 14. Electric field distribution at $[(\mathrm{a}),(\mathrm{d})] 5.5 \mathrm{GHz}[(\mathrm{b}),(\mathrm{e})]$ $14.3 \mathrm{GHz}$ and $[(\mathrm{c}),(\mathrm{f})] 20 \mathrm{GHz}$ for TM and TE polarized wave incidence, respectively.

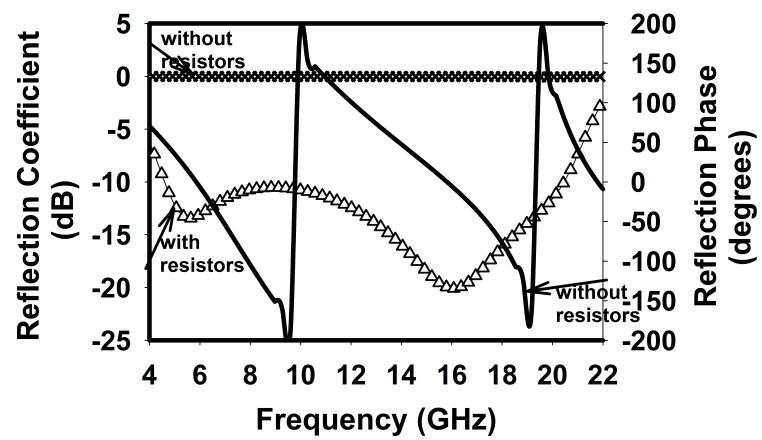

Fig. 15. Comparison of reflectivity of the structures with and without resistors.

\section{Measured Results and Discussions}

To experimentally validate the wideband absorption characteristics of the structure, a prototype is fabricated. The total dimension of the structure is taken as $21 \mathrm{~cm} \times 21 \mathrm{~cm}$ constituting 289 unit cells. 1156 SMD chip resistors with case code type of 0402 (Vishay-CRCW0402220RFKED) are soldered on to the four legs of each cross loop unit cell. The nylon spacers are used to maintain an air gap of $4.7 \mathrm{~mm}$ between the FSS layer and metal ground plane. The front and side view of the fabricated prototype is shown in Fig. 16(a) and (b), respectively.

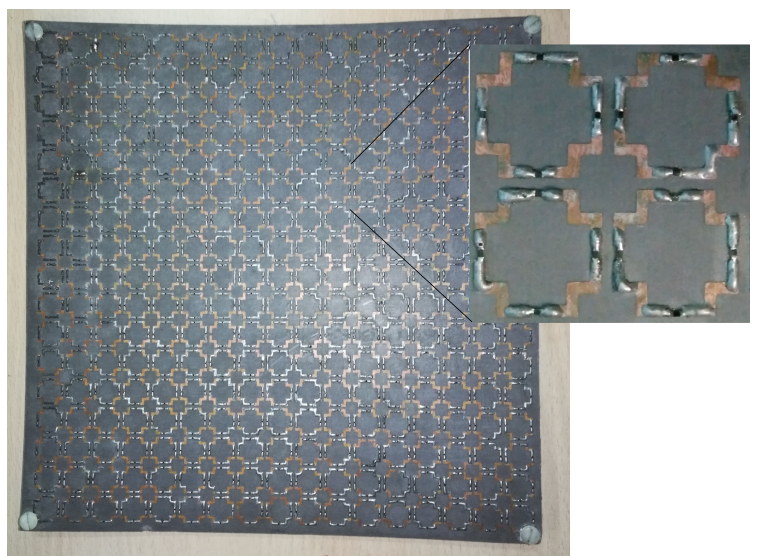

(a)

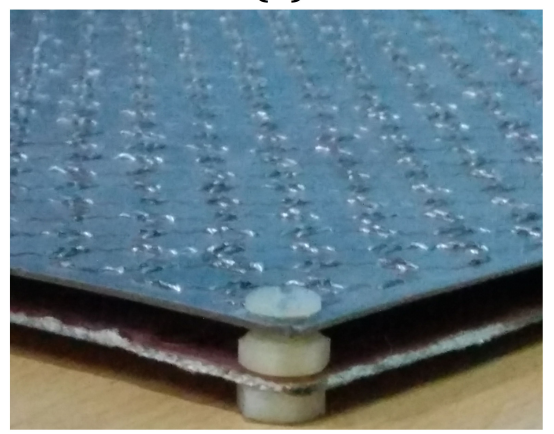

(b)

Fig. 16. Photograph of the fabricated prototype (a) Front view (b) side view. 


\begin{tabular}{|c|c|c|c|c|}
\hline Ref & Unit cell size $[\mathrm{mm}]$ & Thickness $[\mathrm{mm}]$ & $\mathbf{- 1 0 ~ d B ~ b a n d w i d t h ~ [ \% ] ~}$ & Unit cell characteristics \\
\hline$[28]$ & 13.6 & $.077 \lambda_{\mathrm{L}}$ & 70.7 & Single layer, 4 resistors \\
\hline$[35]$ & 24.3 & $14.7\left(0.088 \lambda_{\mathrm{L}}\right)$ & 126.8 & Single layer+ spacer, 16 resistors \\
\hline$[36]$ & 12 & $3\left(0.08 \lambda_{\mathrm{L}}\right)$ & 73.68 & Single layer, 8 resistors \\
\hline$[37]$ & 40 & $10\left(.085 \lambda_{\mathrm{L}}\right)$ & 75 & Single layer, 8 resistors \\
\hline$[38]$ & 13 & $4.6\left(0.076 \lambda_{\mathrm{L}}\right)$ & 114.4 & Two layer, 12 resistors \\
\hline Proposed work & 12 & $\left.5.49\left(.0841 \lambda_{\mathrm{L}}\right)\right)$ & 126.5 & Single layer +Spacer, 4 resistors \\
\hline
\end{tabular}

Tab. 1. Comparison of the performance of proposed absorber with previous works.

The performance of the structure is measured using two wideband horn antennas ((Verdant JR-18 that works from $2 \mathrm{GHz}-18 \mathrm{GHz}$ ) connected to Rohde \& Schwarz ZVB 20 vector network analyzer. All the measurements are carried out in an anechoic environment. The reflected power from an identical metal plate is measured and normalized to nullify the cable and other losses. The photograph of the measurement set up is shown in Fig. 17. Measurements are taken up to $18 \mathrm{GHz}$ due to the frequency limit of antenna.

The measured reflection coefficient of the structure compared to simulated response is shown in Fig. 18. The observed deviation may be due to fabrication error, soldering inaccuracy or resistor value variations.

The polarization insensitivity of the structure is also measured for normal incidence and is depicted in Fig. 19. The structure exhibits polarization independent characteristics.

\section{Conclusion}

A wideband circuit analog absorber composed of crossed loop loaded with lumped resistors is presented in this paper. The proposed absorber has thickness of $0.084 \lambda_{\mathrm{L}}$ and it offers $-10 \mathrm{~dB}$ reflection bandwidth from $4.6 \mathrm{GHz}$ to $20.45 \mathrm{GHz}$, which corresponds to a fractional bandwidth of $126.5 \%$. The effect of polarization and incident angle on the absorption property of the structure is also studied. Compared to the previously reported structures, the proposed absorber has simple structural geometry, lesser number of resistors per unit cell and enhanced bandwidth. A prototype of the structure is fabricated and it is observed that the measured results are in a general agreement with the simulation.

\section{Acknowledgments}

Authors would like to acknowledge the financial and infrastructural support from University Grants Commission and Department of Science and Technology, Government of India. The authors also would like to thank Rogers Corporation for providing the substrate under University sample program.

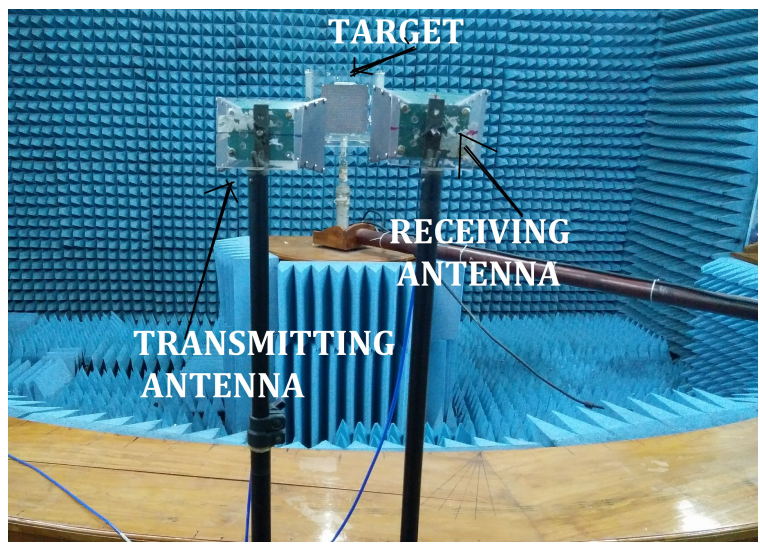

Fig. 17. Experimental set up.

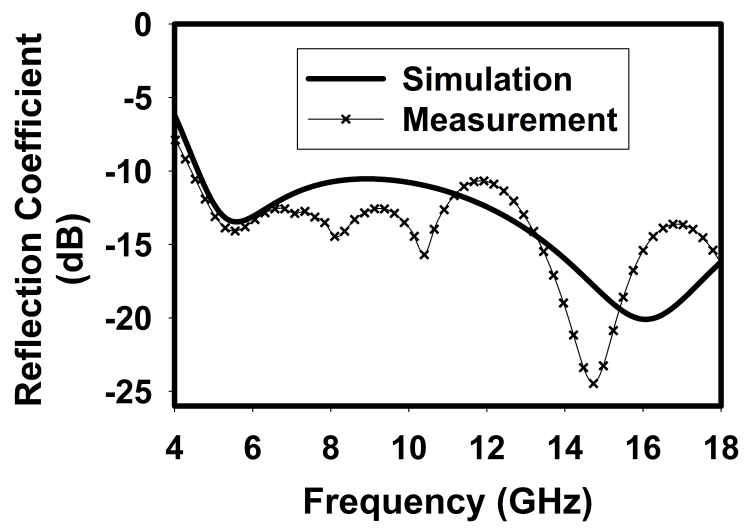

Fig. 18. Comparison of measured and simulated reflection coefficient.

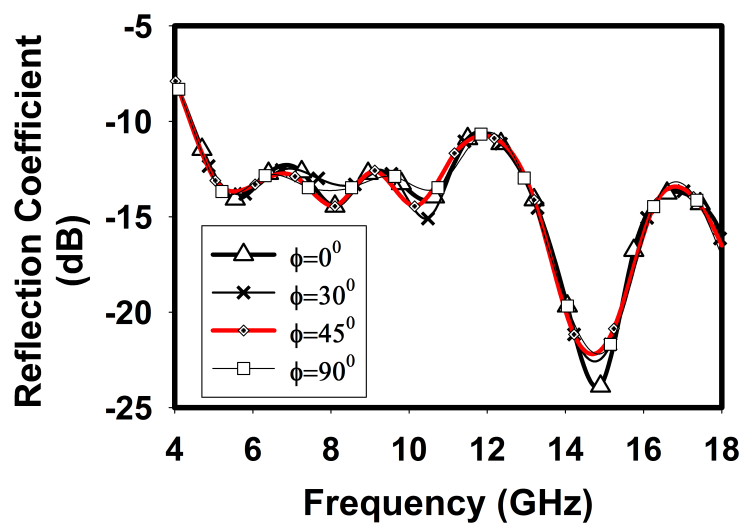

Fig. 19. Measured reflection coefficient for different polarization angles. 


\section{References}

[1] FANTE, R. L., McCORMACK, M. T. Reflection properties of the Salisbury screen. IEEE Transactions on Antennas and Propagation, 1988, vol. 36, no. 10, p. 1443-1454. DOI: 10.1109/8.8632

[2] DU TOIT, L. J., CLOETE, J. H. A design process for Jaumann absorbers. In Proceedings of the Digest on Antennas and Propagatiovn Society International Symposium. San Jose (USA), 1989, p. 1558-1561. DOI: 10.1109/APS.1989.135020

[3] VALAGIANNOPOULOS, C. A. Electromagnetic absorption of gaussian beams by a grounded layered structure. Radioengineering, 2013, vol. 22, no. 1, p. 333-340.

[4] SIEVENPIPER, D., ZHANG, L., BROAS, R., et al. High impedance electromagnetic surfaces in a forbidden frequency band. Transactions on Microwave Theory and Techniques, 1999, vol. 47, no. 11, p. 2059-2074. DOI: 10.1109/22.798001

[5] COSTA, F., MONORCHIO, A. Electromagnetic absorbers on high impedance surfaces: From ultra narrowband to ultra wideband absorption. Advanced Electromagnetics, 2012, vol. 1, no. 3, p. 7-12. DOI: $10.7716 /$ aem.v1i3.22

[6] CHRONOPOUlOS, S. K., CHRISTOFILAKIS, V., TATSIS, G., et al. Performance of turbo coded OFDM under the presence of various noise types. Wireless Personal Communications,2016, vol. 87, no. 4, p. 1319-1336. DOI: 10.1007/s11277-015-3055-1

[7] CHRONOPOULOS, S, K., VOTIS, C., RAPTIS, V. In depth analysis of noise effects in orthogonal frequency division multiplexing systems, utilising a large number of subcarriers. AIP Conference Proceedings, 2010, vol. 1203, no. 1, p. 967-972. DOI: $10.1063 / 1.3322592$

[8] RAPTIS, V., TATSIS, G., CHRONOPOUlOS, S., et al. Development and experimental measurements of a tunable antenna. Communications and Network, 2013, vol. 5, no. 3, p. 220-224. DOI: $10.4236 / \mathrm{cn} .2013 .53026$

[9] HAN, T., CAO, X., GAO, J., et al. Design of a novel wideband low-scattering shared aperture metasurface. Radioengineering, 2017, vol. 26, no. 4, p. 1006-1012, DOI: 10.13164/re.2017.1006

[10] LANDY, N. I., SAJUYIGBE, S., MOCK, J. J., et al. Perfect metamaterial absorber. Physical Review Letters, 2008, vol. 100, no. 20, p. 207402. DOI: 10.1103/PhysRevLett.100.207402

[11] MUNAGA, P., GHOSH, S., BHATTACHARYYA, S., et al. An ultrathin dual-band polarization-independent metamaterial absorber for EMI/EMC Applications. In Proceedngs of the $9^{t h}$ European Conference on Antennas and Propagation (EuCAP). Lisbon (Portugal), 2015, p. 1-4.

[12] CHAURASIYA, D., GHOSH, S., BHATTACHARYYA, S., et al. An ultrathin quad-band polarization-insensitive wide angle metamaterial absorber. Microwave and Optical Technology Letters, 2015, vol. 57, p. 697-702. DOI: 10.1002/mop. 28928

[13] HUANG, L., CHEN, H. Multi-band and polarization insensitive metamaterial absorber. Progess in Electromagnetic Research, 2011, vol. 113, p. 103-110. DOI: 10.2528/PIER10122401

[14] JANG, Y., YOO, M., LIM, S. Conformal metamaterial absorber for curved surface. Optics Express, 2013, vol. 21, no. 20, p. 24163-24170. DOI: 10.1364/OE.21.024163

[15] GHOSH, S., BHATTACHARYYA, S., CHAURASIYA, D., et al. Polarization- insensitive and wide-angle multilayer metamaterial absorbers with variable bandwidths. IET Electronic Letters, 2015, vol. 51, no. 14, p. 1050-1052. DOI: 10.1049/el.2015.1167
[16] MA, B., LIU, S., BIAN, B., et al. Novel three-band microwave metamaterial absorber. Journal of Electromagnetic Waves and Applications, 2014, vol. 28, no. 12, p. 1478-1486. DOI: 10.1080/09205071.2014.929050

[17] SHARMA, S. K., GHOSH, S., SRIVASTAVA, K. V., et al. Ultrathin dual-band polarization-insensitive conformal metamaterial mbsorber. Microwave And Optical Technology Letters, 2017, vol. 59, no. 2, p. 348-353. DOI: 10.1002/mop.30285

[18] KIM, J., HOKMABADI, M. P., BALCI, S., et al. Investigation of robust flexible conformal $\mathrm{THz}$ perfect metamaterial absorber. Applied Physics A, 2016, vol. 122, no. 4, p. 1-7. DOI: $10.1007 / \mathrm{s} 00339-016-9857-5$

[19] DIAZ, R. Magnetic loading of artificial magnetic conductors for bandwidth enhancement. In Proceedings of the IEEE Antennas and Propagation Society International Symposium. Columbus (USA), 2003, vol. 2, p. 431-434. DOI: 10.1109/APS.2003.1219268

[20] KERN, D. J., WERNER, D. H. Magnetic loading of EBG AMC ground planes and ultrathin absorbers for improved bandwidth performance and reduced size. Microwave and Optical Technology Letters, 2006, vol. 48 , no. 12 , p. 2468-2471. DOI: $10.1002 /$ mop. 21972

[21] YANG, H., CAO, X., GAO, J., et al. Low RCS metamaterial absorber and extending bandwidth based on electromagnetic resonances. Progress in Electromagnetic Research M, 2013, vol. 33, p. 31-44. DOI: 10.2528/PIERM13080104

[22] BHATTACHARYYA, S., GHOSH, S., SRIVASTAVA, K. V. Triple band polarization-independent metamaterial absorber with bandwidth enhancement at X-band. Journal of Applied Physics, 2013, vol. 114, no. 9, article ID 094514. DOI: 10.1063/1.4820569

[23] GHOSH, S., BHATTACHARYYA, S., SRIVASTAVA, K. V. Bandwidth-enhancement of an ultra-thin polarization insensitive metamaterial absorber. Microwave and Optical Technology Letters, 2014, vol. 56, no. 2, p. 350-355. DOI: $10.1002 / \mathrm{mop} .28122$

[24] KUNDU, D., MOHAN, A., CHAKRABORTY, A. Ultrathin polarization independent absorber with enhanced bandwidth by incorporating giusepe peano fractal in square ring. Microwave and Optical Technology Letters, 2015, vol. 57, no. 5, p. 1072-1078. DOI: $10.1002 / \mathrm{mop} .29020$

[25] LI, M., XIAO, S., BAI, Y. Y., et al. An ultrathin and broadband radar absorber using resistive FSS. IEEE Antennas and Wireless Propagation Letters, 2012, vol. 11, p. 748-751. DOI: 10.1109/LAWP.2012.2206361

[26] ZHANG, G. R., ZHOU, P. H., ZHANG, H. B., et al. Analysis and design of triple-band high-impedance surface absorber with periodic diversified impedance. Journal of Applied Physics, 2013, vol. 114, p. 164103 . DOI: $10.1063 / 1.4826265$

[27] KIM, B. K., LEE, B. Wideband absorber at X-band adopting trumpet-shaped structure. Electronics Letters, 2014, vol. 50, no. 25, p. 1957-1959. DOI: 10.1049/el.2014.2780

[28] KUNDU, D., MOHAN, A., CHAKRABARTY, A. Single-layer wideband microwave absorber using array of crossed dipoles. IEEE Antennas and Wireless Propagation Letters, 2016, vol. 15, p. 1589-1592. DOI: 10.1109/LAWP.2016.2517663

[29] MUNAGA, P., GHOSH, S., BHATTACHARYYA, S., et al. A fractalbased compact broadband polarization insensitive metamaterial absorber using lumped resistors. Microwave and Optical Technology Letters, 2016, vol. 58, no. 2, p. 343-347. DOI: 10.1002/mop.29571

[30] GHOSH, S., BHATTACHARYYA, S., SRIVASTAVA, K. V. Design and analysis of a broadband single layer circuit ana$\log$ absorber. In Proceedings of the 46th European Microwave Conference (EuMC). London (UK), 2016, p. 584-587. DOI: 10.1109/EuMC.2016.7824410 
[31] WU, W., CUI, K., LU, H., et al. A measured rasorber with two absorptive bands. Radioengineering, 2017, vol. 26, no. 4, p. 979-983. DOI: $10.13164 /$ re.2017.0979

[32] MENG, T., WU, W., YUAN, N. The design and analysis of invisible radome with sandwich-like properties. Radioengineering, 2017, vol. 26, no. 2,p. 423-429. DOI: 10.13164/re.2017.0423

[33] LI, S., CAO, X., GAO, J., et al. Fractal metamaterial absorber with three-order oblique cross dipole slot structure and its application for in-band rcs reduction of array antennas. Radioengineering, 2014, vol. 23 , no. 4 , p. $1048-1054$

[34] LI, S., CAO, X., LIU, T., et al. Double-layer perfect metamaterial absorber and its application for res reduction of antenna. Radioengineering, 2014, vol. 23, no. 1, p. 222-228.

[35] SHANG, Y., SHEN, Z., XIAO, S. On the design of single-layer circuit analog absorber using double-square-loop array. IEEE Transactions on Antennas and Propagation, 2013, vol. 61, no. 12, p. 6022-6029. DOI: 10.1109/TAP.2013.2280836

[36] LI, S., GAO, J., CAO, X., et al. Wideband, thin, and polarizationinsensitive perfect absorber based the double octagonal rings metamaterials and lumped resistances. Journal of Applied Physics, 2014, vol. 116 , no. 4 , article ID 043710. DOI: $0.1063 / 1.4891716$

[37] YANG, J., SHEN, Z. A thin and broadband absorber using doublesquare loops. IEEE Antennas and Wireless Propagation Letters, 2007, vol. 6, p. 388-391. DOI: 10.1109/LAWP.2007.903496

[38] GHOSH, S., BHATTACHARYYA, S., SRIVASTAVA, K. V. Design, characterisation and fabrication of a broadband polarisationinsensitive multi-layer circuit analogue absorber. IET Microwaves, Antennas and Propagation, 2016, vol. 10, no. 8, p. 850-855. DOI: 10.1049/iet-map.2015.0653
[39] COSTA, F., MONORCHIO, A., MANARA, G. Analysis and design of ultra thin electromagnetic absorbers comprising resistively loaded high impedance surfaces. IEEE Transactions on Antennas and Propagation, 2010, vol. 58, no. 5, p. 1551-1558. DOI: 10.1109/TAP.2010.2044329

\section{About the Authors...}

Libi Mol V. ABDUL HAKIM received the Master of Technology in Electronics from Cochin University of Science and Technology (CUSAT), India, in 2012. She is currently a research scholar at Department of Electronics, CUSAT. Her research interests include radar cross section reduction, artificial magnetic conductor, frequency selective surfaces and antennas, etc..

C. K. AANANDAN received the M.Sc. and Ph.D. degrees from Cochin University of Science and Technology (CUSAT), Cochin, India, in 1982 and 1987 respectively. $\mathrm{He}$ is currently working as the professor in department of electronics, CUSAT. He has published over 100 academic journals and conference papers and led numerous funded projects from the government organizations and industry. $\mathrm{He}$ has over 30 years research experience in microstrip antennas, radar cross section studies, conducting polymers, microwave measurements, computational electromagnetics, frequency selective surfaces, etc.. 